\title{
A paisagem sonora religiosa ${ }^{1}$
}

\author{
Marcos Alberto Torres ${ }^{2}$
}

${ }^{2}$ Doutorando e Mestre em Geografia pela UFPR.E-mail: torresmarcos@hotmail.com

Recebido em 04/2012. Aceito para publicação em 12/2012.

Versão online publicada em 01/02/2013 (http://seer.ufrgs.br/paraonde)

\begin{abstract}
Resumo - Os espaços religiosos são produtores de paisagens sonoras que envolvem seus fiéis, ao passo que comunicam valores e conecta-os ao sagrado, o que contribui para a identificação entre o ser religioso e o espaço religioso e, consequentemente, com o espaço sonoro nele e por ele produzido. 0 espaço religioso possibilita que os fiéis frequentadores compartilhem experiências e memórias, o que concede identidade ao grupo de religiosos e à religião. 0 presente artigo tece relações entre a paisagem sonora produzida nos espaços religiosos e o ser religioso, tendo como premissa a ideia de que as paisagens sonoras atuam na construção de paisagens da memória, imprescindíveis à construção identitária do ser religioso.
\end{abstract}

Palavras-chave: Paisagem Sonora. Espaço Religioso. Identidade Religiosa.

\section{Introdução}

Adentrar um espaço religioso implica adentrar um universo de sons, que se distinguem daqueles que acontecem fora de suas paredes. Tal multiplicidade de sons e sonoridades, aqui denominada paisagem sonora religiosa, envolve seus fiéis por meio dos diferentes elementos que a compõem, o que faz dela portadora de mensagens e significados que participam da identidade do espaço religioso e do ser religioso. Dentre as múltiplas sonoridades que os espaços religiosos comportam, tem-se os sons produzidos por instrumentos musicais e os sons produzidos pelos seres humanos, por meio das vozes ou do movimento do corpo. Cada espaço religioso apresenta ainda especificidades e particularidades nos sons que produz, guardando semelhanças entre as religiões de mesmas denominações e raízes, e diferenças entre as demais.

A paisagem sonora, que, na perspectiva de Murray Schafer (2001) é compreendida como todos os sons de um ambiente, quando produzida no interior de um espaço religioso, envolve os fiéis freqüentadores. Tais freqüentadores, por sua vez, identificam-se com o espaço sonoro, reconhecem e interpretam cada som e cada música, e também são capazes de interpretar e interagir em cada momento do culto, o que confere a identificação entre o ser religioso e o espaço religioso e, consequentemente, com o espaço sonoro nele e por ele produzido. Dessa forma, as paisagens sonoras atuam na construção de paisagens da memória, imprescindíveis à construção identitária do ser religioso. No presente artigo objetiva-se apontar algumas das relações existentes entre a paisagem sonora e a construção da identidade religiosa.

As paisagens sonoras podem revelar importantes elementos de identificação do ser religioso com o espaço religioso que freqüenta, e podem contribuir à compreensão do universo simbólico de cada indivíduo, o que permite estabelecer relações com a espacialidade do sagrado no cotidiano do ser religioso. Para Cassirer (1994), as atividades humanas definem o "ciclo da humanidade", e estão pautadas no sistema simbólico, que é a capacidade de imaginação e inteligências simbólicas.

É no espaço religioso que os fiéis freqüentadores compartilham experiências e memórias, o que contribui para a construção da identidade do grupo de religiosos e à religião, e também para a construção da ideia de mundo, pois os fatos e momentos compartilhados no espaço religioso

${ }^{1}$ Uma primeira versão deste artigo foi apresentada sob o título de "A PAISAGEM SONORA E A IDENTIDADE RELIGIOSA: possíveis conexões" no IX Encontro Nacional da Associação de Pós-Graduação e Pesquisa em Geografia, realizado no ano 2011 na cidade de Goiânia, Goiás. A presente versão abarca as contribuições obtidas no Grupo de Trabalho "Espaço e Representações" do referido evento. 
somam-se às demais experiências pessoais. Lowenthal (1982), ao discorrer sobre a contribuição da experiência na composição da idéia de mundo afirma que os lugares em que freqüentamos, visitamos ou percorremos, até mesmo os que lemos e vemos pelas mídias, e os domínios da imaginação, contribuem para as nossas imagens de natureza e do homem. Assim, para este autor, todos os tipos de experiências, desde as mais estreitamente ligadas com o nosso mundo diário até aquelas que parecem remotamente distanciadas, vêm juntos compor o nosso quadro individual da realidade (LOWENTHAL, 1982, p. 141). As identidades associam-se ao espaço, pois se baseiam nas lembranças divididas, nos lugares percorridos, nos monumentos que retratam os grandes momentos do passado, nos símbolos gravados nas pedras das esculturas ou nas inscrições (CLAVAL, 1997, p. 107). Nos espaços religiosos, as lembranças e as histórias fazem-se compartilhar também por meio da paisagem sonora, seja na oralidade, seja por meio das músicas.

A paisagem sonora apresenta-se à Geografia como importante campo de estudo, pois, assim como a olfativa, age profundamente no indivíduo para a lembrança de um lugar. Para Waterman (2006, p. 01) os sentidos da audição e do olfato são capazes de evocar memórias e imagens mais poderosas do que as coisas que vemos, e seus usos seletivos permitem a produção de imagens mais robustas. Para este autor, os olhos fazem a varredura e captam o cenário mais amplo rapidamente, mas os sentidos da audição e do olfato reagem mais lentamente e talvez mais profundamente.

As paisagens sonoras concedem identidades aos lugares, e agem direta e constantemente nas pessoas que se expõem a elas, o que contribui para o compartilhamento e para a perpetuação de valores, gostos musicais, e na evocação de paisagens do passado, o que reforça valores existentes em cada indivíduo, que pode contribuir para sua conversão e/ou identificação a determinadas religiões, e à criação do sentimento de pertencimento a elas, pelo fato de apresentarem sonoridades que concedem familiaridade na paisagem.

Cabe ressaltar que o estudo das religiões em Geografia não deve ser efetuado apenas com base material ou nas coisas visíveis, mas deve também considerar a construção do espaço sagrado por meio da prática religiosa, o que implica adentrar o universo subjetivo do ser religioso, na busca da compreensão das relações religiosas. Segundo Gil Filho (2007),

Tendo em vista que o espaço sagrado é também um produto da prática religio- sa concreta, não é possível a separação entre posição e conteúdo, pois o último parte de uma consciência do vivido plenamente sensível. (...) A cada posição no espaço sagrado convergem valores afetivos específicos atribuídos pelo homem religioso, sendo este, um espaço da intuição que distingue o religioso do não-religioso. (GIL FILHO, 2007,p. 213)

Para a busca da compreensão do homem e de suas ações no campo religioso, faz-se pertinente o pensamento de Ernst Cassirer (1994), para o qual o homem vive em um universo simbólico composto pela linguagem, pelo mito, pela arte e pela religião. Dentro dessa perspectiva os conceitos de percepção, memória e linguagem serão desenvolvidos, confluindo para a inserção das discussões acerca da paisagem sonora e de suas repercussões na identidade do ser religioso.

\section{Formas simbólicas, identidade e cultura}

No livro "Ensaio sobre o homem" Ernst Cassirer (1994) desenvolve a ideia de que o homem não deve ser pensado como um animal racional, $\mathrm{e}$ sim como um animal simbólico, visto que a razão é um termo inadequado para se pensar a cultura humana em sua totalidade. Para este autor, no círculo funcional de todos os animais existe um sistema receptor, através do qual uma espécie biológica recebe os estímulos externos, e um sistema efetuador, pelo qual reage a eles. 0 que difere o homem de outros animais é justamente o sistema simbólico, que é a capacidade de imaginação e inteligência simbólicas. Cassirer conclui que "não estando mais num universo meramente físico, o homem vive em um universo simbólico. A linguagem, o mito, a arte e a religião são partes desse universo" (1994, p. 48). Tais elementos, na concepção de Gil Filho (2008, p. 67), são meios de articulação do processo de significação e ressignificação do mundo, e situam-se na interseção do universo dos fatos com o universo simbólico. Cassirer determina que o universo simbólico é composto de formas simbólicas, entendidas como "meios peculiares que o homem cria para separar-se do mundo com ajuda deles, unindo-se mais firmemente ao mundo precisamente por meio desta separação" (CASSIRER, 2005, p. 38).

A relação do homem com o mundo das coisas coloca em evidência o espaço de representação e as formas que evidenciam a ação do ser humano no espaço, o que implica diretamente na construção da identidade da pessoa que interage com a construção da identidade do grupo e do lugar. A 
identidade e as ações humanas compõem o amálgama da constante busca de liberdade presente nos seres humanos que, segundo Cassirer, é a capacidade de consciência acerca da condição humana, com seus limites e necessidades. É a constante busca pela autoconsciência.

A consciência é o começo e o fim, é o alfa e o ômega da liberdade que ao homem é possibilitada adquirir; o conhecimento e o reconhecimento da necessidade constitui o verdadeiro processo de libertação que o "espírito" pode realizar sobre a "natureza". (CASSIRER, 2005, p. 38) ${ }^{3}$

A autoconsciência implica no reconhecimento do indivíduo como ser atuante na sociedade. Para Di Méo e Buléon (2005, p. 31), é por meio do espaço de ação que os seres humanos territorializam-se, na medida em que a relação privilegiada (de designação, de apropriação, de qualificação) que mantém com seu espaço de ação o transforma em território. Nesse processo, segundo os autores, o indivíduo parte de uma consciência livre para uma consciência de si, etapa que ocorre no campo fenomenológico, que é o campo das experiências particulares, e passam posteriormente pela consciência de indivíduo, pessoa e ator, sendo este último mais próximo da esfera da sociedade organizada em grupos. Assim, o sujeito que parte de uma consciência de si, com suas geograficidades, portador de uma identidade individual, segue para a consciência de sociedade na qual está inserido como ator - sujeito em ação - agora com identidade social. Dentro desse processo, sujeito e sociedade interagem constantemente, o que reflete na compreensão e apropriação do espaço por meio das territorialidades.

Para o ser religioso, é o convívio com a comunidade religiosa que permite a troca de informações, a manutenção dos valores sociais e religiosos, e o compartilhamento de memórias, todos essenciais à manutenção do sentimento de pertencimento a ela. Na concepção de Gil Filho,

O desenvolvimento da identidade religiosa está condicionado a uma determinada temporalidade e espacialidade e perpassa o reconhecimento institucional da religião. Já a ideia de pertença permite um reconhecimento não necessariamente institucional da opção religiosa. A identidade religiosa refere-se a uma imagem institucional necessária e demonstra a materialidade da religião e a representação pela qual o indivíduo e o grupo se identificam.

Todavia, ao destacarmos a identidade religiosa, também estamos diante de uma construção que remete à materialidade histórica, à memoria coletiva, à espacialidade da própria revelação religiosa processada em determinada cultura. (GIL FILHO, 2008, p. 83)

Para que haja a formação de grupos sociais e a interação entre o sujeito e a sociedade, é necessária a existência de uma linguagem ou de linguagens (forma simbólica) que permitam a comunicação entre as pessoas. Tais linguagens, quando exercidas em um determinado território, manifestamse na paisagem de diferentes maneiras, desde, por exemplo, os tipos de vestimentas utilizadas por um grupo de religiosos que se territorializa em um local público para a realização de um evento religioso e informam/comunicam "aos outros" que ali, naquele dado momento, será o território de tais pessoas e para tal fim. No plano da paisagem sonora, a comunicação pode acontecer na oralidade dos sermões e de outras formas de discursos, ou ainda por meio das músicas, o que denota o diálogo entre diferentes formas simbólicas, mas que juntas apontam para a intencionalidade do ser religioso, que busca compreender, e explicar o que compreende, da natureza que o contém. Para Cassirer,

O ideal só existe representado de algum modo material, acessível aos sentidos e encarnado nesta representação. A religião, a linguagem, a arte: todos eles são acessíveis para nós através dos monumentos que cada uma dessas manifestações vão criando e que são os signos, os vestígios do pensamento e da recordação sem os quais não poderíamos chegar a captar jamais um sentido religioso, lingüístico ou artístico. (CASSIRER, 2005, p. 62)

0 entrelaçamento dos elementos que compõem as formas religiosas nos permite reconhecer um objeto cultural (ou objetos culturais), logo, manifestam-se na paisagem por meio de diferentes formas, e participam da construção da identidade religiosa, que está pautada na construção e compartilhamento de memórias e das percepções vividas por cada integrante da comunidade.

\footnotetext{
${ }^{3}$ Tradução livre.
} 


\section{Percepção e memória}

As experiências pessoais definem o primeiro contato com o mundo, e a experiência corporal fornece a base para a imaginação e construção ou reconstrução de fatos do passado. É também através da experiência corporal que o indivíduo percebe uma paisagem e resignifica-a a cada novo contato. Desse modo a percepção está relacionada à experiência corporal, como afirma Merleau-Ponty ao relacionar imaginação e experiência corporal: "toda percepção exterior é imediatamente sinônima de uma certa percepção de meu corpo, assim como toda percepção de meu corpo se explicita na linguagem da percepção exterior" (MERLEAUPONTY, 2006, p. 277). Assim, o que se tem início nas experiências corporais culmina na construção da percepção, que se vincula às experiências compartilhadas entre as pessoas de um mesmo convívio social. Ao explicar o espaço sagrado, Gil Filho (2007, p. 213) afirma que "o espaço sagrado estaria muito mais próximo de um espaço da percepção, do que os espaços concebidos pelo intelecto".

As experiências vividas e compartilhadas pelas pessoas religiosas incluem as mediadas pelos meios de comunicação, quando presentes no cotidiano dessas pessoas. No entanto, as experiências com o meio constituem forte elemento na construção da visão do mundo. No compartilhamento das histórias de vida, dos acontecimentos e dos fatos vividos, cada indivíduo constrói imagens acerca do que é relatado. Tais imagens, segundo Cassirer (2001, p. 211), são produtos da capacidade empírica da imaginação produtiva.

A percepção e a memória integram o complexo das relações sociais e espaciais, e interagem nelas. Ambas, percepção e memória, são elementos de cada indivíduo e também da coletividade. São, dessa forma, essenciais ao estudo da cultura, pois estão ligadas ao processo criativo. Assim evidencia-se a complexidade existente na relação homem - meio, já que mesmo na experiência corporal do ser humano, este sofre influências de suas experiências anteriores, dos lugares, e da coletividade a que se relaciona. Segundo Cassirer,

A critica do conhecimento mostra que a simples sensação na qual está pressuposta apenas uma qualidade sensível, mas nenhuma forma de ordenação, não é, de maneira nenhuma, um "fato" da experiência imediata, constituindo, tão-somente, o resultado de uma abstração. A matéria da sensação nunca está dada pura em si e "anteriormente" a toda e qualquer conformação; ao contrário, já a partir do momento de sua primeira percepção, ela se insere em uma relação com as formas espaço e tempo. (CASSIRER, 1994, p. 205)

Gil Filho, ao explanar sobre o pensamento Cassireriano, conclui que "o homem é dotado além do sistema receptivo e do relativo, do sistema simbólico que o capacita a superar os limites da realidade natural e galgar uma nova dimensão da realidade" (GIL FILHO, 2007, p. 220). No espaço sagrado o homem religioso compartilha do sistema simbólico na busca da compreensão da realidade. Segundo Gil Filho (2007, p. 214), "o espaço se apresenta como o meio universal onde objetivamos nossa apreensão do real em múltiplos ordenamentos", o que vai ao encontro do exposto por Halbwachs acerca do compartilhamento de um mesmo lugar por um grupo humano, ao afirmar que "quando um grupo humano vive por muito tempo em um local adaptado a seus hábitos, não apenas seus movimentos, mas também seus pensamentos se regulam pela sucessão das imagens materiais que os objetos exteriores representam para ele" (HALBWACHS, 2006, p. 163). Assim, faz-se necessário considerar as práticas pessoais vividas pelo homem religioso, que conflitam e confluem para uma construção identitária na religião a que pertence, pois "os costumes locais resistem às forças que tendem a transformá-los e essa resistência permite entender melhor a que ponto nesse tipo de grupo a memória coletiva se apóia nas imagens espaciais" (HALBWACHS, 2006, p. 162). Lowenthal afirma que "o passado é parte integrante de nosso sentido de identidade. [...] A identificação das fases anteriores da vida de si mesmo é crucial não só para a integridade, mas também para o bem-estar" (LOWENTHAL, 1998, p. 79).

Por meio da vivência, do compartilhamento dos saberes e dos valores no cotidiano, é constituído em cada indivíduo uma identidade, a qual se reflete na paisagem.

Para que a nossa memória se aproveite da memória dos outros, não basta que estes nos apresentem seus testemunhos: também é preciso que ela não tenha deixado de concordar com as memórias deles e que existam muitos pontos de contato entre uma e outras para que a lembrança que nos fazem recordar venha a ser reconstruída sobre uma base comum. Não basta reconstituir pedaço a pedaço a imagem de um acontecimento passado para obter uma lembrança. É preciso que esta reconstrução funcione a partir de 
dados ou de noções comuns que estejam em nosso espírito e também no dos outros, porque elas estão sempre passando destes para aquele e vice-versa, o que será possível somente se tiverem feito parte e continuarem fazendo parte de uma mesma sociedade, de um mesmo grupo.(HALBWACHS, 2006, p. 39)

Para Cassirer, o processo pelo qual o homem não só repete sua experiência passada, mas também reconstrói essa experiência, é denominado memória simbólica, sendo que "a imaginação torna-se um elemento necessário da verdadeira lembrança" (CASSIRER, 1994, p. 89). Para Almeida, a "imaginação é a faculdade de evocar imagens ausentes, fictícias, irreais, enterradas no nosso mais profundo eu" (ALMEIDA, 2003, p. 73). Como elementos constitutivos da memória, Michael Pollak destaca: "Em primeiro lugar, são os acontecimentos vividos pessoalmente. Em segundo lugar, são os acontecimentos que eu chamaria de 'vividos por tabela', ou seja, acontecimentos vividos pelo grupo ou pela coletividade à qual a pessoa se sente pertencer" (POLLAK, 1992, p. 02).

Os fenômenos que ocorrem diretamente no indivíduo são as sensações e as percepções, e na relação entre o indivíduo e o coletivo está a construção simbólica que, mediada pela imaginação e memória, resultam no espaço abstrato concebido da vida cultural.

É no espaço e no tempo que toda a realidade está contida. Sobre o espaço e o tempo do mundo humano existem, partindo do espaço e tempo orgânicos - que está ligado à adaptabilidade ao meio -, mais quatro espaços: espaço perceptual, simbólico, de ação, e o abstrato, sendo estes dois últimos alguns dos formadores da vida cultural. 0 espaço de ação é o espaço mais primitivo, ligado a interesses práticos e imediatos (CASSIRER, 1994). As sensações e as percepções ocorrem no espaço de ação, por serem fenômenos que ocorrem no indivíduo, sendo, portanto, respostas aos interesses práticos e imediatos.

Para Merleau-Ponty o sentir é a "[...] comunicação vital com o mundo que o torna presente para nós como lugar familiar de nossa vida. É a ele que o objeto percebido e o sujeito que percebe devem sua espessura. Ele é o tecido intencional que o esforço de conhecimento procurará decompor" (2006, p. 84). Para este autor, "perceber no sentido pleno da palavra, que se opõe a imaginar, não é julgar, é apreender um sentido imanente ao sensível antes de qualquer juízo" (2006, p. 63). Da percepção do espaço segue-se uma leitura da paisagem. É da paisagem que o indivíduo extrai suas percep- ções acerca do lugar, dando significados a ele e resignificando seus elementos.

Para um estudo da paisagem que comporte não só as experiências individuais, mas também o universo simbólico, deve-se levar em consideração a comunicação estabelecida entre as pessoas que compõem essa cultura. Para isso, o estudo deve considerar não apenas as percepções e as memórias, experienciadas individualmente e construídas no indivíduo e na coletividade, mas também a linguagem, que media a comunicação estabelecida entre os seres humanos.

\section{A paisagem sonora e a identidade religiosa}

0 conceito de paisagem remete às percepções que se tem sobre uma unidade do espaço, um lugar. Cada paisagem é produto e produtora da cultura. É também unidade de apreensão de uma determinada porção do espaço, e sua descrição e análise estão carregadas dos significados que são atribuídos pelo seu observador, construídos ao longo do tempo. Giuliana Andreotti (2008), entende a paisagem cultural como fato espiritual e psicológico, e, ao refletir sobre a paisagem, entende que o passado não é mais passado, pois estabelece uma relação direta com o observador por via da integração psicológica.

No campo da paisagem sonora, a informação e os significados são sentidos, resultado das ondas sonoras que atingem sensivelmente o corpo de quem a ela se expõe, para então serem decodificados. Para o estudo da paisagem sonora, o recorte de tempo dedicado deve diferenciar-se do tempo destinado ao estudo da paisagem visual, visto que cada paisagem sonora é um evento (ONG apud POCOCK, 1989, p. 193), e pode acontecer em um curto espaço de tempo, o que implica em uma atenção do pesquisador para esse fato. Os estudos que tratam da paisagem sonora devem ainda considerar a música que, no caso religioso, perpetua-se tanto no interior dos templos religiosos como também nas residências e em outros espaços de ação de cada ser religioso. 0 artista responsável pela composição musical, e também aquele que a executa, move-se pelo desejo de transmitir seus sentimentos por meio da linguagem musical.

[...] o artista está sempre animado pela poderosa vontade e a maior capacidade de comunicação. Não descansa nem se sente tranquilo até encontrar o caminho para fazer sentir aos outros o que vive nele. (CASSIRER, 2005, p. 79)

Nos espaços religiosos, a linguagem musi- 
cal carrega-se dos valores simbólicos da comunidade religiosa que se reúne para o culto. Portanto, pode-se afirmar que a paisagem sonora relacionase diretamente às percepções e às memórias do ser religioso.

Para as religiões de origem africana no Brasil, é na paisagem sonora que estão os elementos responsáveis pela sua perpetuação, pois, de acordo com Ferreti (2005, p. 03), "são religiões da oralidade, em que os conhecimentos são transmitidos de boca a ouvido, como um dom transferido de pessoa a pessoa e em que os conhecimentos devem ser guardados de cor, embora parte destes conhecimentos no século XX começam a se tornar escritos". Ao se referir às igrejas pentecostais, ainda que de tradição escrita, o autor também apresenta a relação da religiosidade com elementos da paisagem sonora, ao afirmar que "as igrejas pentecostais têm atraído cada vez maior número de jovens, principalmente através da presença da música, de cânticos, danças e da aceitação de indumentárias modernas" (FERRETI, 2005, p. 07). Nas igrejas católicas, os cantos entoados, as rezas, e o sermão feito pelo padre, apresentam-se como elementos da paisagem sonora, compartilhada entre seus fiéis, assim como os elementos das paisagens sonoras citadas anteriormente às outras religiões são compartilhadas entre seus religiosos frequentadores.

Ainda que compartilhem de ideias e valores com a comunidade religiosa, os indivíduos possuem olhares e representações acerca do espaço sagrado que são singulares. Seus olhares baseiamse em suas experiências e vivências, armazenadas e (re)significadas em suas memórias. As lembranças (instâncias da memória), ao passo em que são compartilhadas, contribuem na formação e reafirmação da cultura e do lugar. Paul Claval afirma que "o sentido de identidade de muitas coletividades sociais está ligado às paisagens da lembrança e da memória" (CLAVAL, 2002, p. 22). Lowenthal, ao citar Boulding, explica que a imagem do meio ambiente "é construída como resultado de toda a experiência passada do possuidor da imagem. Parte da imagem é a história da própria imagem" (LOWENTHAL, 1982, p. 139). No interior dos espaços religiosos, as imagens compartilhadas dizem respeito ao espaço sagrado e às espacialidades e experiências dos indivíduos e da comunidade religiosa. As imagens são compartilhadas tanto por meio de reproduções plásticas, ou mesmo por meio da oralidade, sendo, portanto, imagens mentais. Ecléa Bosi, ao explanar sobre os quadros sociais da memória presentes no pensamento de Halbwachs, explica que "a memória do indivíduo depende do seu relacionamento com a família, com a classe social, com a escola, com a Igreja, com a profissão; enfim, com os grupos de convívio e os grupos de referência peculiares a esse indivíduo" (BOSI, 1994, p. 54). As experiências com os elementos do espaço e com os grupos de convívio proporcionam o contato com o passado, e também a construção de identidades e a apropriação, construção e organização do espaço. Almeida caracteriza o espaço como portador de símbolos e afetividades, que, segundo ela, são atribuídos pelas pessoas ao passo que o espaço torna-se social. (ALMEIDA, 2003, p. 71)

No plano da paisagem, partindo-se da paisagem sonora, a linguagem ocupa lugar ao lado da percepção e da memória na busca de respostas para a compreensão da identidade de cada indivíduo. A linguagem ganha destaque nas músicas, e também no modo de empregar a fala e adotar os discursos religiosos no decorrer do culto religioso. $\mathrm{Na}$ linguagem encontramos os significados para cada coisa e para cada fato experienciado. É por meio dela que a comunicação se estabelece, e que os valores culturais são construídos e repassados. É através da linguagem que se torna possível representar uma coisa distante fisicamente, ou ainda reapresentar um fato vivido.

Por este motivo, também a linguagem
somente se inicia onde termina a rela-
ção imediata com a impressão e a emo-
ção sensíveis. O som emitido ainda não
é o som da linguagem, enquanto ele se
apresentar como repetição pura;
enquanto juntamente com a vontade
de "significação" lhe faltar o específico
momento da significação. A meta da
repetição é a identidade, a meta da
designação lingüística é a diferença. A
síntese que nela se realiza somente
pode efetuar-se como síntese do diver-
so, e não do idêntico àquilo que ele
deseja expressar; quanto mais ele
ainda "é" este outro, tanto menos ele
será capaz de "significar" este outro.
(CASSIRER, 2001,p. 192)

Os sons da fala humana promovem o contato entre as pessoas de uma comunidade religiosa, $\mathrm{e}$ é essencial não apenas para que uma criança, por exemplo, aprenda a desenvolver-se nesse meio, mas também para que haja o compartilhamento das experiências, percepções e memórias de todos os seus fiéis, e a conseqüente construção da identidade religiosa.

O que o som busca é a proximidade 
imediata da impressão sensível e a reprodução tão fidedigna quanto possível da diversidade desta impressão. [...] Aqui, a linguagem ainda adere de tal maneira ao fenômeno concreto e à sua imagem sensível, que ela, por assim dizer, procura esgotá-lo com o som; não se contentando com uma designação geral, ela acompanha cada matiz particular do fenômeno particular, adequando a cada caso específico. (CASSIRER, 2001,p. 194-195)

A fala comunica não apenas a coisa em si, mas uma série de valores de cada cultura, que compõem a expressão simbólica aplicada às palavras que utiliza. Segundo Cassirer,

[...] a língua [...] busca sempre alargar, $\mathrm{e}$ finalmente, romper o círculo desta expressão. Ela transforma a necessária ambigüidade do signo fonético em uma virtude. Porque essa ambigüidade, precisamente, não permite que o signo se conserve como signo individual; é justamente ela que obriga o espírito a dar o passo decisivo que conduz da função concreta do "designar" para a função geral e universalmente válida da "significação". Nela, por assim dizer, a língua se despe dos seus envoltórios sensíveis, nos quais até então se apresentava: a expressão mímica ou analógica cede lugar à expressão puramente simbólica que, precisamente através do seu caráter inteiramente diferente e em razão do mesmo, se torna portadora de um conteúdo espiritual novo e mais profundo. (CASSIRER, 2001,p. 206)

As paisagens sonoras produzidas nos cultos religiosos de diferentes religiões no Brasil tornam perceptíveis suas identidades sonoras, e possibilitam a identificação e o sentimento de pertencimento que o ser religioso expressa. Em contrapartida, é verificável o sentimento de estranheza de um religioso para com as paisagens sonoras de outras religiões que não a sua. Como exemplo, pode-se afirmar que as paisagens sonoras das missas católicas, independente da localidade do templo, apresentam semelhanças, mas quando comparadas a um culto realizado em uma igreja protestante ou em um terreiro de candomblé serão diferentes, o que será suficiente para que o religioso católico não tenha o mesmo sentimento de pertencimento em um espaço religioso que não seja católico.

Mesmo as músicas executadas no interior dos espaços religiosos apresentam sonoridades específicas, oriundas dos instrumentos musicais utilizados para seu acompanhamento. Nas religiões de origem africana no Brasil, os tambores marcam presença constante nos cultos, diferentemente do que ocorre nas missas tradicionais católicas, nas quais as músicas podem ser entoadas sem acompanhamento de instrumentos musicais, ou apenas ao som de um órgão. Já nas igrejas protestantes, os instrumentos musicais elétricos tem se tornado cada vez mais comuns, como o uso de guitarras, contra-baixos e teclados, também acompanhados por instrumentos de percussão, como a bateria. Além das músicas e dos sons dos instrumentos, vale lembrar que a paisagem sonora de um culto religioso apresenta outros elementos, como, por exemplo, nas missas católicas ou cultos protestantes a presença da mensagem, sermão ou pregação.

Diante do exposto, conclui-se que a linguagem não é um simples agregado de sons e palavras, mas um sistema (CASSIRER, 1994, p. 205) que se faz presente na cultura e, portanto, na paisagem.

A paisagem sonora produzida no interior de cada templo religioso expressa os valores de uma dada comunidade religiosa. Os discursos utilizados para tal fim são empregados nos diferentes momentos de comunicação do culto religioso, como nos sermões, nas músicas, ou mesmo no intervalo das músicas, como os que ocorrem nas igrejas protestantes quando um integrante do grupo musical se responsabiliza por conduzir o grupo e a igreja aos louvores, relacionando sempre a música que será cantada a fatos do cotidiano e/ou fatos bíblicos. Para tais situações, verifica-se também o emprego de dois tipos de músicas claramente marcados: as chamadas músicas de louvor, com ritmos mais rápidos e, portanto, mais "agitadas e alegres", e as músicas de adoração, mais lentas. As músicas de louvor marcam o momento de sociabilidade do culto, onde as pessoas acompanham as músicas com as palmas e com pequenas coreografias. Já as músicas de adoração representam momentos mais introspectivos, onde cada fiel interage com a música de maneira mais íntima.

As paisagens mentais podem também ser construídas ou rememoradas pelas pessoas quando escutam músicas religiosas em outros espaços que não os religiosos, como em suas casas ou carros. 0 momento da escuta pode permitir a rememoração de fatos vividos, discursos religiosos e/ou histórias bíblicas que podem ou não relacionaremse entre si. As paisagens religiosas, dessa forma, participam da construção de todo universo simbólico do ser religioso, o qual atribui valores e signifi- 
cados aos elementos que as constituem, baseandose em suas experiências e vivências.

Nos estudos com base na paisagem, a qual comporta os valores culturais, estão expressos em seu complexo a percepção e a memória do seu povo, o que é fundamental para a construção do espaço e da identidade de cada um. Estes elementos são passíveis de serem estudados na busca da compreensão dos seus significados e dos componentes do universo simbólico dos integrantes de uma dada comunidade. Dessa forma a percepção, a memória e a linguagem interagem e encontram-se no universo simbólico, que se apresenta como base para a aproximação dos sentidos e significados, e das relações existentes entre a paisagem sonora e a identidade.

\section{Considerações finais}

As relações existentes entre a paisagem sonora e a identidade religiosa estão atreladas às percepções e memórias de cada ser religioso, o que se integra também às suas práticas cotidianas. A paisagem sonora produzida nos espaços religiosos por meio das músicas e das falas, que cumprem a função de comunicar aos fiéis e também de conduzi-los a uma experiência com o sagrado, muitas vezes ultrapassa as paredes do templo e integramse ao cotidiano do ser religioso, por meio das canções que estão em suas memórias, e que eventualmente "apresentam-se" a ele por meio de programas radiofônicos ou de CD's, ou por meio da palavra sagrada quando algum fenômeno do cotidiano lhe sugere, ou ainda no contato com escrituras sagradas ou nas conversas entre amigos, que confirmam a experiência religiosa por eles vivida.

Desse modo, a paisagem sonora produzida no interior de cada espaço religioso, torna-se elemento essencial às construções de paisagens mentais pelos seus frequentadores, que as relacionam a momentos específicos e podem, por meio delas, conectar-se ao sagrado por meio das sensações e dos significados simbólicos que atribuem a cada fato do cotidiano.

\section{Referências}

ALMEIDA, Maria Geralda de. Em busca do poético do sertão. In: ALMEIDA, M. G. de, RATTS, A. (orgs.). GEOGRAFIA: leituras culturais. Goiânia: Editora Alternativa, 2003.

ANDREOTTI, Giuliana. Paesaggi in movimento, paesaggi in vendita, paesaggi rubati. Trento: Artimedia-Trentini, 2008.
BOSI, Ecléa. Memória e sociedade: lembranças de velhos. São Paulo: Companhia das Letras, 1994.

CASSIRER, Ernst. Ensaio sobre o homem: introdução a uma filosofia da cultura humana. São Paulo: Martins Fontes, 1994.

A filosofia das formas simbólicas.

São Paulo: Martins Fontes, 2001.

Las ciencias de la cultura. México:

FCE, 2005.

CLAVAL, Paul. As abordagens da Geografia Cultural. In: CASTRO, I. E.; GOMES, P. C. da C.; CORRÊA, R. L. (orgs.). Explorações geográficas: percursos no fim do século. Rio de Janeiro: Bertrand Brasil, 1997.

A Geografia Cultural. Florianópolis: EDITORA UFSC, 2001.

.A volta do cultural" na Geografia. Mercator - Revista de Geografia da UFC, ano $01, \mathrm{n}^{\circ}$ 01, 2002. (p. 19 - 27). Disponível em: < http:// www.mercator.ufc.br/> Acesso em: 08/10/2007.

DI MÉO, Guy, BULÉON, Pascal. L'Espace Social: une lecture géographique des sociétés. Paris: Armand Colín, 2005.

FERRETI, Sérgio. Religiões afro-brasileiras e pentecostalismo no fenômeno urbano. In: Simpósio da Associação Brasileira de História das Religiões. 0 sagrado e o urbano: desafios contemporâneos de análise, 2005, Belo Horizonte. Anais... Belo Horizonte: 2005. Disponível em < http:// www.gpmina.ufma.br> Acesso em: 21 de julho de 2009.

GIL FILHO, Sylvio Fausto. Geografia da Religião: Reconstruções teóricas sob o idealismo crítico. In: KOZEL, S.; COSTA, J.; GIL FILHO, S. F. (orgs.). Da percepção e cognição à representação: reconstruções teóricas da Geografia Cultural e Humanista. São Paulo: Terceira Imagem; Curitiba: NEER, 2007.

Espaço sagrado: estudos em geografia da religião. Curitiba: IBPEX, 2008.

HALBWACHS, Maurice. A memória coletiva. São Paulo: Centauro, 2006.

LOWENTHAL, David. Geografia, experiência e imaginação: em direção a uma epistemologia geográfica. In: CHRISTOFOLETTI, A. (org.). Perspectivas 
da Geografia. São Paulo: Difusão Editorial, 1982.

El pasado es um país extraño.

Madrid: Ediciones Akal, 1998.

MERLEAU-PONTY, Maurice. Fenomenologia da

percepção. São Paulo: Martins Fontes, 2006.

POCOCK, Douglas. Sound and the Geographer. Journal of the Geographical Association. № 324, Vol. 74, Part 3. June 1989.

POLLAK, Michel. Memória e identidade social. Estudos Históricos, Rio de Janeiro, vol. 5, n 10, 1992, p.
200-212. Disponível em: <www.cpdoc.fgv.br/ revista> Acesso em: 23/11/2007.

SCHAFER, R. Murray. A afinação do mundo: uma exploração pioneira pela história passada e pelo atual estado do mais negligenciado aspecto do nosso ambiente: a paisagem sonora. São Paulo: Editora da UNESP, 2001.

WATERMAN, Stanley. Geography and music: some introductory remarks. GeoJournal, Springer Netherlands, vol. 65, fevereiro 2006.

\title{
The religious soundscape
}

\begin{abstract}
The religious places produce soundscapes that involve their people, and transmit values and connect them with the sacred, which contributes to the identification between being religious and the religious space and, consequently, with the sound space in and through it produced. The religious space allows the sharing of experiences and memories, providing the basis for the construction of group identity and religion. This article explores the relationship between the soundscape produced in religious spaces to be religious, taking as its premise the idea that the soundscapes act in the construction of landscapes of memory, essential to the identity construction of being religious.
\end{abstract}

Keywords: Soundscape. Religious Space. Religious Identity.

\section{Le paysage sonore religieux}

Résumé - Les espaces religieux sont des producteurs sonores qui impliquent ses fidèles, une fois qu'ils communiquent des valeurs et les relient au sacré, ce qui contribue à l'identification entre l'être religieux et l'espace religieux et, par conséquent avec l'espace sonore produit en lui et pour lui. L'espace religieux permet que les fidèles partagent des expériences et des souvenirs qui accordent l'identité au groupe religieux et à la religion. Cet article explore la relation entre le paysage sonore produit aux espaces religieux et l'être religieux, en prenant comme postulat l'idée que des paysages sonores agissent sur la construction des paysages de la mémoire, indispensables à la construction de l'identité de l'être religieux.

Mots-clés: Paysages Sonores, L'espace Religieux. L'identité Religieuse. 